\title{
Technology of impact assessment of energy on region's environment
}

\author{
Vladimir R. Kuzmin ${ }^{l}$, Liudmila V. Massel ${ }^{l}$ \\ ${ }^{1}$ Melentiev Energy Systems Institute SB RAS, 664058, Irkutsk, Lermontova str., 130
}

\begin{abstract}
Nowadays, the problems of the impact of pollutants' emissions from industrial facilities, which include energy facilities, are attracting more and more attention in the world. Different international and governmental organizations issue decrees and recommendations on pollutants emission reduction. This, in turn, requires technologies and tools to assess the impact of current facilities, develop recommendations for them to reduce the emissions, and perform evaluation of impact for planned facilities. This article discusses a proposed technology for impact assessment of energy facilities on region's environment, methods that are used by this technology. Also, architecture and main components of the scientific prototype of intelligent decision-making support system to support this technology are provided and results of approbation are shown.
\end{abstract}

\section{Introduction}

According to the Energy strategy of the Russian Federation until 2035 [1], ones of the priorities are: moving to the environmentally friendly and resourcesaving energy (1) and rational use of natural resources and energy efficiency (2). National project "Ecology" provides the elimination of the most dangerous objects of accumulated harm to the environment and the ecological improvement of water bodies (including lake Baikal) and halving the emission of hazardous pollutants that have the greatest negative impact on the environment and human health until 2024 [2]. Thus, the problem of assessing the impact of pollutants is very urgent.

Nowadays, environmental assessments of the energy objects are carried out through measurements and continuous monitoring as well as with usage of statistical information, State Reports, and energy objects' reports. [3]. In case of the absence of reliable information, the assessment of the impact of energy sector can be carried out according to the results of a computational experiment using existing methods, approved by Russian government. Existing methods, that are used for impact assessment of energy objects, are applied separately and this fact complicates the process of such complex research, and we could not find information on integration of these methods.

In this article, we propose technology for impact assessment of energy on region's environment and discuss methods, tools, and information technologies for support of this technology.

\section{State of art}

Currently, the issues of the impact of emissions of pollutants from industrial facilities, which include energy facilities, are attracting more and more attention.

Models such as HYSPLIT and AERMOD are widely used for calculating the dispersion of pollutant emissions.

Hybrid Single-Particle Lagrangian Integrated Trajectory (HYSPLIT) is a complete system for computing simple air parcel trajectories as well as complex transport, dispersion, chemical transformation, and deposition simulations [4], which was developed by the National Oceanic and Atmospheric Administration (NOAA) Air Resources Laboratory's (ARL), USA. One of the most common model applications is a backtrajectory analysis to determine the origin of air masses and establish source-receptor relationships [5]. It is also used for such simulations as: describing the atmospheric transport, dispersion, and deposition of pollutants and hazardous materials. For example, in [6] HYSPLIT is used for production of operational atmospheric trajectory and dispersion forecasts twice daily. The developed system supports research applications and emergency response events that require modelling the transport and dispersion of harmful pollutants released to the atmosphere. In article [7], to find out the characteristics and sources of atmospheric pollutants, researchers investigated the temporal and spatial distribution of pollutants, using data of typical atmospheric pollutants (such as $\mathrm{SO}_{2}, \mathrm{NO}_{2}, \mathrm{PM}_{10}$, and $\mathrm{CO}$ ). Then, these features were combined with the HYSPLIT model for backward trajectory simulation of heavily polluted weather.

Although, HYSPLIT gained wide usage, it is not preferred or recommended model for regulatory purposes by U.S. Environmental Protection Agency (U.S. EPA). 
Main considerations are that the model is unable to account for secondary chemical reactions and relies on the input meteorological data's resolution, which can have coarse temporal and spatial resolution. U.S. EPA prefers to use AERMOD [8], atmospheric dispersion modeling system is an integrated system that consists of three modules [9]: steady-state short-range dispersion model of air pollutant emissions, meteorological data preprocessor (AERMET), and terrain preprocessor (AERMAP). In research [10] AERMOD was used for evaluation of the concentrations resulting from the simulation and to make comparisons with allowable levels according to current law. In [11] AERMOD was used for management of building construction because dust and emissions from destruction and construction activities (such as $\mathrm{PM}_{10}$ and $\mathrm{PM}_{2.5}$ ) can worsen the quality of air which can harm to health and impact upon life quality. In article [12], AERMOD is used for the identification of a point-source release. For this purpose, an inversion technique based on the least squares approach is adopted. Study showed that its source location had estimated with an average error about $25 \mathrm{~m}$ from the real value and the corresponding max and min errors were $57 \mathrm{~m}$ and $10 \mathrm{~m}$, respectively. And study, described in [13] shows that the use of different elevation datasets did not influence the evaluation results of the AERMOD model in a local scale and complex terrain significantly.

In Russia, methods of calculation of spreading of harmful emissions in the atmosphere (or MRR-2017) is used often. MRR-2017 allows to calculate maximal onetime concentration from the point of emission and long-periodic average concentration, calculate spreading of harmful emissions considering terrain and weather data [14]. In [15] it was used as a part of the project for implementation of instrumental monitoring of atmospheric air pollution. Researchers in [16] reported that they used MRR-2017 for calculation of threshold limit values. These methods were also used for identification of the most contributing pollutants and placing of air monitoring stations [17].

Research of impact of energy on region's environment were also discussed in [18-20].

\section{Proposed technology}

Proposed technology for impact assessment of energy on region's environment consists of three stages:

- Quantitative calculation of pollutants emission.

- Performing of spreading calculation of pollutants.

- Comparison of the obtained results with the snow measurements results.

We assume that this technology can be used to conduct complex interdisciplinary research at the intersection of ecology and energy, and for correct work with this technology, it will be necessary to attract specialists from these areas.

Now we will take a closer look at each stage of the technology.

\subsection{Quantitative calculation of pollutants emission}

At first stage of proposed technology quantitative calculation of pollutants emission is performed. This calculation utilizes methods for determining emissions of pollutants into the atmosphere during fuel combustion in boilers, developed by NII "Atmosphere" [21].

To perform such calculations utilizing this method it is required to provide information about technical characteristics of energy facilities (boiler types, type, classes, and amount of fuel burned, facility's capacity and dust-removal percentage) and data on fuels' characteristics (e.g., humidity for working condition, ash content for dry condition, heat of combustion for working condition, etc.).

Support for this stage of the calculation requires an inventory base of energy facilities, types of boilers and fuels, which contains their technical characteristics, a database of sources about the characteristics of fuel, tools for interacting with them, as well as tools for creating, storing, and viewing the obtained calculation results.

\subsection{Calculation of pollutants spreading}

At second stage calculation of pollutants spreading is performed - maximal onetime concentration from the point of emission and long-periodic average concentration. Calculation utilizes methods of calculation of spreading of harmful emissions in the atmosphere (MRR-2017) [14].

This calculation requires following information:

- Calculation results from previous stage (amounts of pollutants emitted).

- Weather data (air temperature in facility's area, speed, and direction of a wind) obtained from open access sources.

- Technical characteristics of energy facilities (height and diameter of its chimney(-s), temperature of the outgoing gas-air (dust-gas-air) mixture)

From the technical side, to perform calculations at this stage, we will need to have inventory base of energy facilities, described at the previous stage, that will include additional data on facility geographic coordinates (1), tools for results management (creation, storage, and visualization of the obtained results) (2), and weather database with sufficient frequency (frequency is understood as the time interval after which information is updated) - at least once every twelve hours, although, for greater accuracy, it is advisable to use sources with a frequency of four to six hours.

\subsection{Storage of pollutants measurement in snow}

At this step, user may add the results of snow measurements and/or compare them with the results of pollutants emission spreading, obtained on previous stage.

Results of snow measurements contains data on concentration of different pollutants (e.g., $\mathrm{SO}_{4}, \mathrm{NO}_{\mathrm{X}}$, $\mathrm{HCO}_{3}$, etc.) obtained from a set of measurement points. 
To support this stage, we need to implement database for storage of snow measurements results and tools for adding and displaying of this data.

As can be seen from the description of the stages of technology, its application requires information technology and tools for organizing and supporting research. For this, a scientific prototype of the intelligent decision-making support system (IDSS) WIS was implemented, which will be discussed in the next chapter.

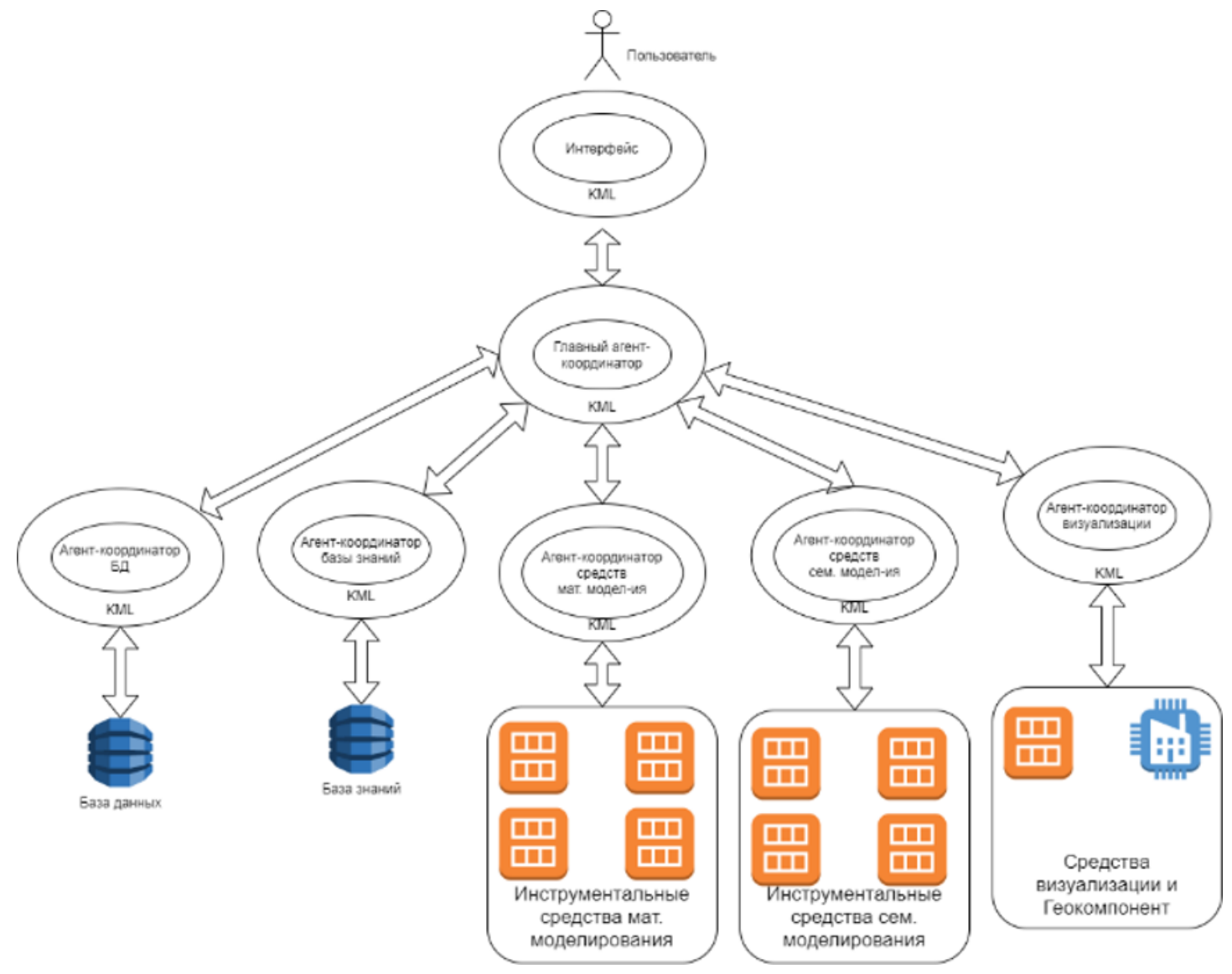

Fig. 1. Architecture of IDSS "WIS"

\section{Information tools}

As we mentioned in previous chapter, to support proposed technology, we had developed scientific prototype of IDSS WIS. Fig. 1. shows its architecture.

System is implemented using agent-service approach for IDSS development [22, 23] which, in turn, is based on approach proposed in [24]. As it can be seen from the architecture it consists of five main services:

- Database service

- Knowledge base service

- Mathematical modelling tools service

- Semantic modelling tools service

- Service of tools for results' visualization and geovisualization.

For proposed technology support, as a part of "WIS", we developed a set of basic components:

- Component for quantitative calculation of pollutants emission

- Component for calculation of spreading of pollutants emission

- Component for work with snow measurements
- Component that handles visualization and geovisualization

- Utilities for work with database of energy facilities, boilers characteristics, types, and parameters of fuels

\section{Calculation example}

In this article we will briefly discuss approbation of the proposed technology and developed IDSS. For approbation we will use data on energy facilities located in Baikal Nature Territory. Test set contains 48 energy facilities with different parameters and burn coal. In this article we will omit the moment of filling in the database of energy objects and fuels

Firstly, we need to perform quantitative calculation of pollutants emission Fig.2 and fig.3 demonstrate preliminary calculation results made by the system. This calculation shows that one of the most polluted zones at Baikal Nature Territory is located nearby Slyudyanka city, one may see it both from table representation and geovisualization (the redder - the more pollutants were emitted in this area). 


\begin{tabular}{|c|c|c|c|c|c|c|c|}
\hline Facility & Fuel & Total emission, thous.t/year & Dust & Sulfur oxides & Nitrogen oxides & Dust removal, \% & Capacity, Gcal/h \\
\hline Region: Irkutsk oblast & & 7.317575 & 5.961276 & 1.300957 & 0.055342 & & 113.620000 \\
\hline District: Slyudyanka & & 6.079552 & 5.045781 & 0.980360 & 0.053411 & & 94.770000 \\
\hline City: Slyudyanka & & 5.303344 & 4.482024 & 0.770399 & 0.050921 & & 77.580000 \\
\hline Fac.: Slyudyanka orphanage & & 0.103188 & 0.071940 & 0.031200 & 0.000048 & & 1.000000 \\
\hline Boiler 1 & Azeyski Coal & 0.051594 & 0.035970 & 0.015600 & 0.000024 & 0 & 0.500000 \\
\hline Boiler 2 & Azeyski Coal & 0.051594 & 0.035970 & 0.015600 & 0.000024 & 0 & 0.500000 \\
\hline Fac.: Medical reserve & & 0.046726 & 0.042434 & 0.004200 & 0.000092 & & 1.200000 \\
\hline Boiler 1 & Azeyski Coal & 0.023363 & 0.021217 & 0.002100 & 0.000046 & 0 & 0.600000 \\
\hline Boiler 2 & Azeyski Coal & 0.023363 & 0.021217 & 0.002100 & 0.000046 & 0 & 0.600000 \\
\hline Fac.: Mntn pass & & 0.723100 & 0.596094 & 0.118000 & 0.009006 & & 11.200000 \\
\hline
\end{tabular}

Fig. 2. Table representation of obtained results

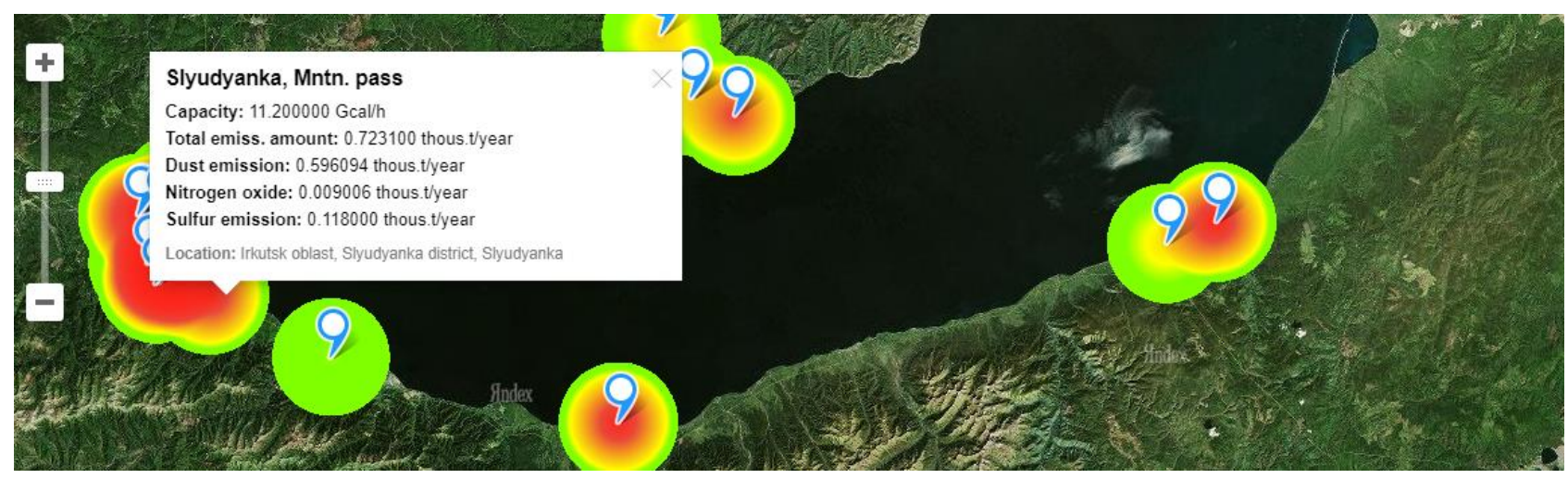

Fig. 3. Geovisualization of calculation results

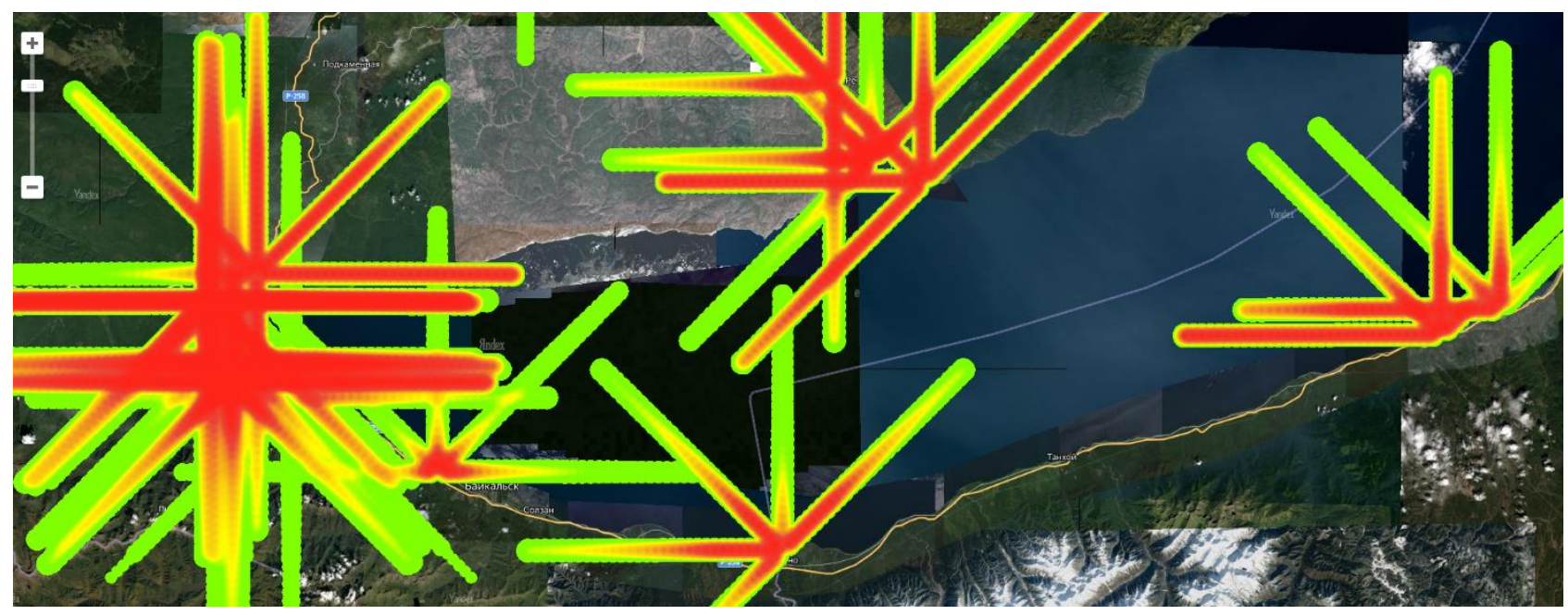

Fig. 4. Geovisualization of calculation results

On stage 2, we will calculate spreading of pollutants from energy facilities using results from the first step and weather data. Fig.4 shows spreading of pollutants in April 2021. The results being displayed are preliminary, because now, model does not account terrain which may lead to not accurate enough. That can be seen, for example, at left part of fig.4 where spreading distance will be less due to mountains around Slyudyanka.

\section{Conclusions and future work}

The article considered the proposed technology for assessing the impact of energy facilities on the environment, as well as methods and information tools to support the described technology. The proposed technology makes it possible to assess the impact of both existing energy facilities and calculate emissions from the planned facilities. The system also allows to develop recommendations for reducing the harmful effects of emissions from energy facilities, for example, by installing additional filters or changing the fuel class.

In the future, we plan to improve the module for calculating the dispersion of emissions of harmful substances to consider the terrain, as well as add support for additional models for the quantitative calculation of emissions of pollutants and the calculation of dispersion of emissions, for example, such models as HYSPLIT or AERMOD. 
Authors thank the staff of the ISEM SB RAS. Discussions of scientific problems have contributed a lot to formulating the results presented in this article.

The research was carried out under State Assignment Project (no. FWEU-2021-0007 AAAA-A21121012090007-7), some aspects were made as part of following project, supported by RFBR grant №19-0700351 .

\section{References}

1. "Energy Strategy of the Russian Federation until 2035", decree of the Russian Federation Government no.1523-p dated 09.06.2020 Available at http://government.ru/docs/all/128340/ (in Russian)

2. National project "Ecology". Available at: https://www.economy.gov.ru/material/file/fbad8a780 cfe43d0d4e807eb166ae5fb/NP_EKO_241218.pdf (in Russian)

3. L.V. Massel et.al. Methods and technologies for assessing the impact of energy on the geoecology of the region: a scientific collective monograph (Chartaraget Publishing House, Yerevan, 2019) (in Russian)

4. A.F. Stein, R.R Draxler, G.D. Rolph, B.J.B. Stunder, M.D. Cohen, F. Ngan, Bulletin of the American Meteorological Society. 96 (12), pp. 2059-2077. (2015). DOI: 10.1175/BAMS-D-14-00110.1

5. Z. L. Fleming, P. S. Monks, A. J. Manning, Atmos. Res., 104-105, pp. 1-39. (2012), DOI: 10.1016/j.atmosres.2011.09.009.

6. L. Chang, N. Jiang, S. Watt, M. Azzi, M. Riley, X. Barthelemy, CASANZ 2021: the 25th Intl. Clean Air and Envt. Conference, 6 p. (2021)

7. Y. Ma, M. Wang, Sh. Wang, Y. Wang, L. Feng \& Wu, W. Kaiyu, Environmental Monitoring and Assessment. 193, 9 (2021) DOI: 10.1007/s10661-02008767-4.

8. U.S. Environmental Protection Agency, 2015. Guidance on the use of models for assessing the impacts of emissions from single sources on the secondarily formed pollutants ozone and $\mathrm{PM}_{2.5}$. Available https://www.epa.gov/sites/production/files/202009/documents/epa-454_r-16-005.pdf

9. AERMOD: DESCRIPTION OF MODEL FORMULATION. Available at: https://nepis.epa.gov/Exe/ZyPDF.cgi/P1009OXW.P DF?Dockey=P1009OXW.PDF

10. J. Cerqueira, H. Albuquerque, F. Sousa, Air Quality, Atmosphere \& Health. 12. pp. 21-32 (2019), DOI: 10.1007/s11869-018-0626-9.

11. R Gopi et al, IOP Conf. Ser.: Mater. Sci. Eng., 1145 $012106 \quad$ (2021), DOI: 10.1088/1757$899 X / 1145 / 1 / 012106$
12. G. Pandey, M. Sharan, Air Quality, Atmosphere \& Health. 14. pp. 679-690 (2021), DOI: 10.1007/s11869-020-00971-y.

13. M. Rzeszutek, A. Szulecka. IOP Conference Series: Earth and Environmental Science. 642, 012014. (2021), doi: 10.1088/1755-1315/642/1/012014.

14. Decree of Ministry of Natural Resources and Environment of the Russian Federation no. 273, dated 06.06.2017 "On Approval of Methods for Calculation of Emissions of Harmful (Polluting) Substances in the Atmospheric Air". Available at: http://publication.pravo.gov.ru/Document/View/0001 201708110012 (in Russian)

15. R.R. Shagidullin, A.F. Gilyazova, A.R. Magdeeva et al., Chemistry and Environmental Engineering XVIII: Proceedings of the International Scientific Conference, pp. 361-364 (2018) (in Russian)

16. Yu.I. Belaya, L.V. Korzhova, Environmental Readings - 2018: The International Scientific and Practical Conference is dedicated to the 100th anniversary of the formation of the P.A. Stolypin Omsk State Agrarian University, pp. 33-36 (2018) (in Russian)

17. I.V. Tikhonova, D.V. Goryaev, M.A. Zemlyanova, S. $\mathrm{Yu}$. Balashov, Topical issues of risk analysis in ensuring the sanitary and epidemiological well-being of the population and protecting consumer rights: Materials of the IX All-Russian Scientific and Practical Conference with International Participation, pp.225-228 (2019) (in Russian)

18. B.G. Saneev, E.P. Maysyuk, I. Yu. Ivanova, Bulletin of the Academy of Sciences. Energy. 6, pp.79-85 (2016) (in Russian)

19. E.P. Maysyuk, Geography and natural resources, 1, pp.100-107 (2017) DOI:10.21782/GiPR0206-16192017-1(100-107) (in Russian)

20. L.V. Massel, I.Yu. Ivanova, T.N. Vorozhtsova, E.P. Maysyuk, A.K. Izhbuldin, T.G. Zorina, A.R. Barsegyan, Ontology of Designing, T.8, 4 (30), pp. 550-561 (2018) DOI: 10.18287/2223-9537-2018-8-4550-561 (in Russian)

21. The methodology for determining emissions of pollutants into the atmosphere when burning fuel in boilers with a capacity of less than 30 tons of steam per hour or less than 20 Gcal per hour, 53 p., (Moscow, 1999) (in Russian)

22. A.G. Massel, V.I. Galperov, V.R. Kuzmin, Proceedings of the VIth International workshop "Critical Infrastructures in the Digital World" (IWCI2019), pp. 211-215 (2019), DOI: 10.2991/iwci19.2019 .37

23. V.R. Kuzmin, Yu.A. Zagorulko, Vestnik NSU. Series: Information Technologies, 18 (3), pp. 5-18, (2020), DOI: $\quad 10.25205 / 1818-7900-2020-18-3-5-18 \quad$ (in Russian) 
24. L.V. Massel, V.I. Galperov, Bulletin of the Tomsk Polytechnic University, Geo Assets Engineering, 326 (5), pp. 45-53 (2015) (in Russian) 